\title{
INVESTIGATION OPTIMISE PARAMETER OF UPPER CONTROL ARM FOR MINING BREAKER
}

\author{
Mayur S.Aware ${ }^{1}$, W.S.Rathod ${ }^{2}$ \\ ${ }^{I}$ Student (Mechanical Machine Design Engineering), Department of Mechanical Engineering, Veermata Jijabai \\ Technological Institute, Mumbai, Maharashtra, India \\ ${ }^{2}$ Assistant Professor in Mechanical Engineering, Department of Mechanical Engineering, Veermata Jijabai \\ Technological Institute, Mumbai, Maharashtra, India
}

\begin{abstract}
Suspension system of automobile is always responsible for safety and driving comfort as the suspension carries the entire vehicle body and transmits all forces between road and body. Suspension system absorbs the vibrations due to rough terrains or road disturbances. Suspension system also provides stability under different conditions like accelerating, uneven road, cornering, braking, loading and unloading. for the vehicles of mining there is no such a suspension system exist as they stands at single point very long, to provide suspension system for the portable mining Breakers as lots of fatigue to human worker working with it. Control arm is important part of suspension system as it joints steering knuckle to vehicle frame. In automotive industry structure optimization techniques was used for light weight and performance improvement of modern new cars. However, static load conditions could not represent all the various situations of automobile parts which subjected to complex loads those varying with time, especially in case of crusher and for lower control arm of front suspension. This paper deals with transient structural analysis of the upper control arm of double wishbone suspension and modal analysis was carried out using ANSYS software for the mining Breaker. Optimization of upper control arm was carried out by selecting better material for weight reduction and better strength. Testing was carried out on Universal testing machine to validate analysis results.
\end{abstract}

Keywords: - Double wishbone suspension, mining, Breaker, Modal analysis, Steering knuckle, Transient structural analysis, ANSYS software, Universal testing machine

\section{INTRODUCTION}

Control arm is one of the most important part of any suspension system. It is made from the materials like steel, iron or aluminum. Arm is vital part for each vehicle on the road. Vehicle can results in annoying vibrations and undesirable driving irregularities that could sometimes cause to road accidents like collision with another vehicle or obstacle on road if there is no suspension arm. Suspension arm is fitted in different types of suspensions such as wishbone or double wishbone, Macpherson strut suspension. In Macpherson strut system maximum load is transferred tire to ball joint and in double wishbone maximum load is transferred from upper to lower arm which responsible for failure and twisting of lower arm at ball joint locations as well as control arm because of impact load. As in case of mining stone breakers, heavy working equipments are install at front side so maximum load can be transfer at front side of crusher ,but as of now there is no such suspension system in Breakers there is huge challenge to transfer heavy shock and load to the ground so to develop and changes in existing design of control arm use in a automotive suspension it is mandatory to focus on stress and deformation study of upper control arm. For transient structural analysis, modal analysis, optimization of upper control arm finite element approach is used.

\section{LITERATURE REVIEW}

The different work method to be carried out on control arm of system in recent years. Jagwinder Singh et al. [1] works on -Static Structural Analysis of Suspension Arm Using Finite Element Methodll. In this work the static structural analysis was done to find out the stress, deformation and safety factor of component and optimization approach is carried out to increase the structural strength of the component. Gurunath Biradar et al. [2] works on -Life Estimation Of Double Wishbone Suspension System of Passenger Carl. In this thesis focus was on the modal analysis and statically analysis of upper arm, lower arm and steering knuckle. Fatigue analysis of existing double wishbone suspension system and modify the design using software's namely Unigraphics, Hypermesh, Optistruct and nCODE. A. Rutci [3] works on -Failure Analysis of a Lower Wishbonell. Paper describes failure analysis of a lower wishbone in a light commercial vehicle has done which involved in service loading. To investigate reason of the failure, finite element analysis is done to evaluate stress distribution and reliability of wishbone. Furthermore, the metallographic and hardness evaluation were done on weld seam of the failed part. Finite Element Analysis and metallographic examination results showed that fatigue failure was occurred from highly stressed region in weld seam. Jong-kyu Kim et al. [4] paper 
describes shape of upper control arm was determined by applying the optimization technology. Study considers the static strength of arm in the optimization process. In this study, the kriging interpolation method is acquired to obtain the minimum weight satisfying the static strength constraint. The real experiments on $1 / 4$ car is conducted to validate the FEM analysis. At last, the correlation of each case about durability life is obtained. B. Sai Rahul et al. [5] paper shows works that ,I Fatigue Life Analysis of Upper Arm of Wishbone Suspension Systemll. In this characterization of the dynamic behavior and investigation of fatigue life of upper suspension arm is done. This study estimate the fatigue life of control arm. The results, thus obtained, can significantly reduce the cost and times to market improve product reliability. Prof. A. M. Patil et al. [6].This paper shows the stress strain analysis study of lower wishbone arm to improve and modify the existing design. The result obtained using finite element analysis approach. Lihui Zhao etal. [7] works on —Dynamic Structure Optimization Design of Lower Control Arm Based on ESLll. Lower control arm dynamic optimization was performed by incorporating traditional static load optimization techniques and multi-body dynamics by Equivalent Static Load (ESL) in this paper and the best draw- bead distribution of the stamped lower control arm was acquired. An optimized and existing result by comparison shows that the strength and stiffness was increased significantly while the mass was almost unchanged. N.A. Kadhim et al. [8] Fatigue life of lower suspension arm has been studied under different amplitude loadings. To obtain the material monotonic properties, tensile test has been carried out and to specify the material mechanical properties of the used material, a fatigue test under constant amplitude loading has been carried out using the ASTM standard specimens. Then, the results used in the finite element software to predict fatigue life has been evaluated later to show the accuracy and efficiency of the numerical models which they are appreciated. V.V. Jagirdar et al. [9] paper describes Wishbone structure for double wishbone front- independent suspension for a military truck. A double wishbone, double coil spring with twin damper configuration was employed for military truck application. MBD Analysis was done using ADAMS software. For the front axle of the vehicle double wishbone independent suspension has been designed. Y. Nadot et al. [10] an experimental device has been developed to study fatigue phenomena for nodular cast iron automotive suspension arms. A methodology is proposed to define the maximum defect size allowable in a casting component. It correlates the empirical method proposed by Murakami to determine the evolution of the fatigue limit with defect size and a multi axial endurance criterion based on the Dang Van model. Validation of the proposed approach gives encouraging results for surface defects and constant amplitude proportional loading.

\section{PROBLEM DEFINITION}

\subsection{Problem Statement}

In suspension system control arm is vital component. As the vehicle goes through bumps, speed breaker etc. some kinds of forces are to be transmitted from car wheels which get transferred to control arm via ball joint assembly to wheel.At constructional and Crushing site there is no such suspension system provided for the equipment so to aim is to provide suspension system for Breaker. General vehicle Control arms can bend or break when driving over large potholes, bumps while brushing can also wear out. Sometimes due to combination of forces like pitching, rolling, acceleration breakdown occurs due to large stress.

Problem statement: - To optimize and design the upper control arm of suspension system for portable mining Breakers with modeling and transient structural analysis of arm based on material. Modal analysis is done in addition. Further optimize arm validated by experimentation.

\subsection{Objective}

- Investigate stress and deformation of Existing Upper Control arm used in automotive.

- Upper control arm optimization using modeling and Transient Structural Analysis.

- Designing and Modal analysis is performed to study the Natural Frequencies of control arm.

- Experimental testing is done to validate analysis results of optimize control arm.

\section{FORCE CALCULATION}

\subsection{Condition I: Static Condition}

The earth's gravitational pull $(\mathrm{mg}=\mathrm{W})$ acts through the centre of gravity and the reaction acts through the contact patches between the tires and the road in general transport vehicle. To every action there is an equal and opposite reaction Figure shows the forces on a stationary car. The vectors shown represent the combined reactions at both front wheels (Rf) and both rear wheels $(\mathrm{Rr})$.
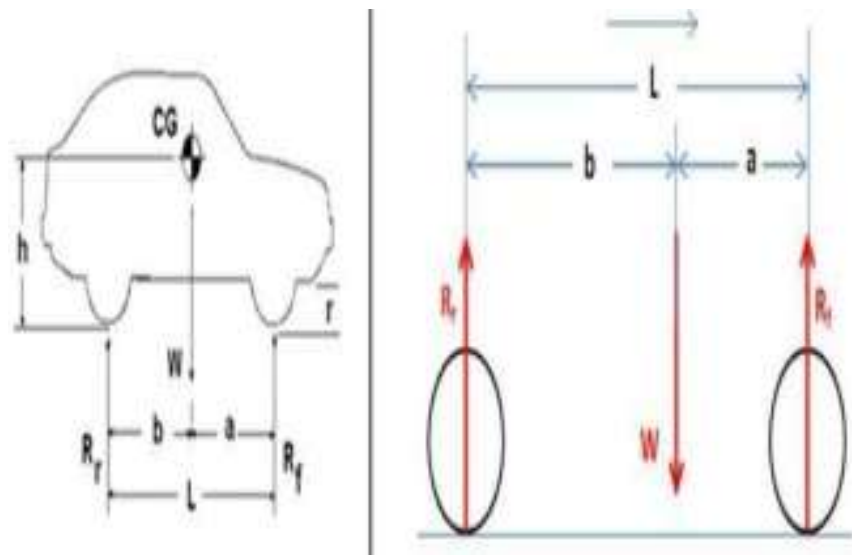

Fig 1: Forces on Stationary Car Total weight of the car = $2300 \mathrm{~kg}=22563 \mathrm{~N}$ 
Weight must be divided into front axle weight and rear axle weight. $52 \%$ of total weight is taken by front axle and $48 \%$ of total weight is taken by rear axle.

Weight on Front axle $=2300 * 0.52=1196 \mathrm{~kg}=11732.76$ $\mathrm{N}$ Weight on Rear axle $=2300 * 0.48=1104 \mathrm{~kg}=10830.24$ $\mathrm{N}$

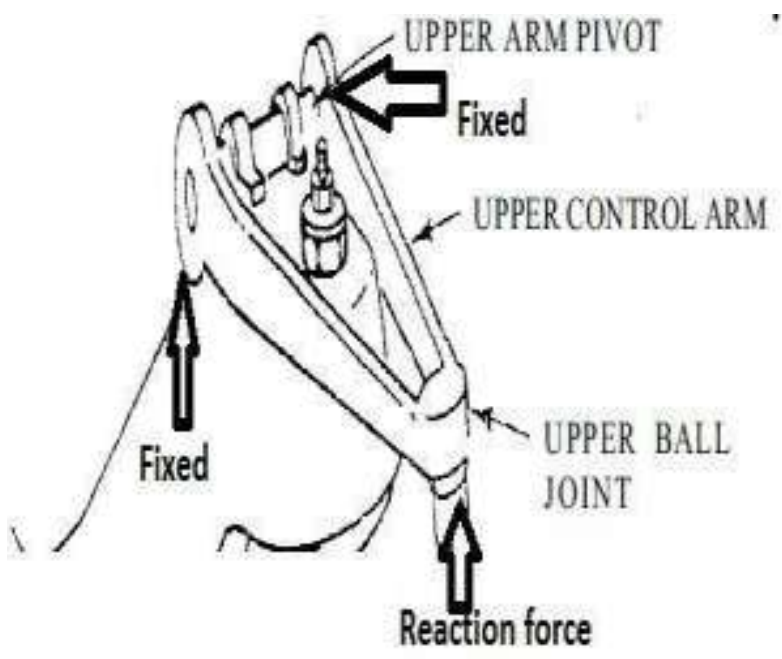

Fig 2: Boundary forces for Static Condition

\subsection{Condition II: Static and Dynamic Loads}

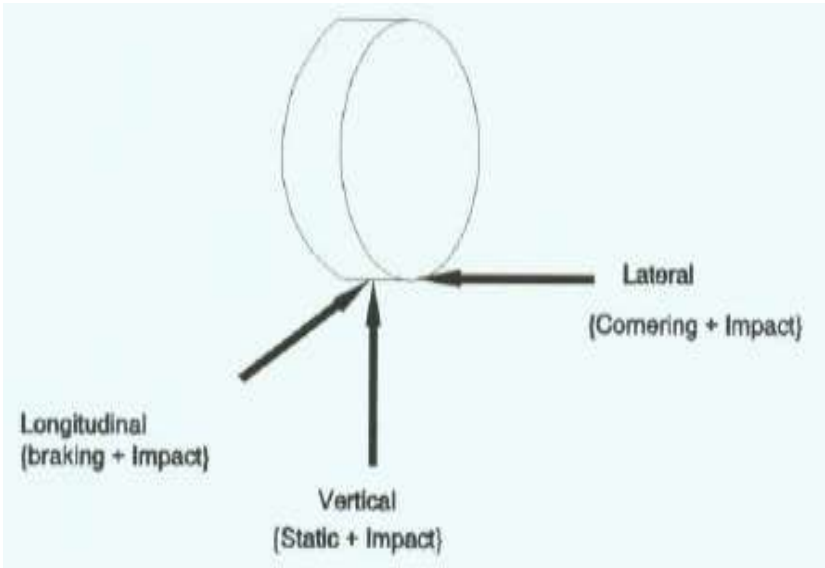

Fig 3: Wheel Loads and Directions

Table 1: Input Parameters for Load Calculations

\begin{tabular}{|l|l|l|}
\hline Description & Symbol & Value \\
\hline Total Weight of vehicle & W = F & $22.563 \mathrm{KN}$ \\
\hline Weight on front axle & $\mathrm{F} 1$ & $11732.76 \mathrm{~N}$ \\
\hline Weight in rear axle & $\mathrm{F} 2$ & $10830.24 \mathrm{~N}$ \\
\hline Tyre rod coefficient & $\mu$ & 1.45 \\
\hline Wheel Base & & $2680 \mathrm{~mm}$ \\
\hline Average acceleration & $\overline{\mathrm{a}}$ & $2.0 \mathrm{~m} / \mathrm{s}^{2}$ \\
\hline Vehicle mass & $\mathrm{m}$ & $1680 \mathrm{~kg}$ \\
\hline Centre of gravity height & $\mathrm{hcg}$ & $880 \mathrm{~mm}$ \\
\hline
\end{tabular}

\subsection{Front Axle Breaking Force (FB) per Wheel}

We have to find the term bcg, consider a simply supported beam, where force $\mathrm{F}=22.56 \mathrm{KN}$ which acts at a distance $\mathrm{X}$ from point $\mathrm{A}$ (Front end)

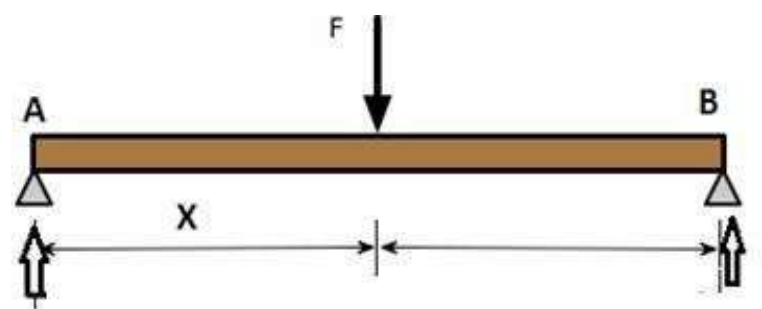

Fig 4: Force on the Axle Simply supported beam Taking moment at point $\mathrm{A}$

$\Sigma \mathrm{mA}=22.56 * \mathrm{X}-10.83 * 2680=0 \mathrm{X}=1286.54 \mathrm{~mm} . \mathrm{bcg}$ $=2680-X=1393.46 \mathrm{~mm}$

$\mathrm{FB}=\mu / 2[$ Static + dynamic load $] \mu / 2\left[\mathrm{~W}^{*}\right.$ bcg $/ 1+\mathrm{m}^{*} \overline{\mathrm{a}}$ $* \mathrm{hcg} / \mathrm{l}] \mu / 2 \mathrm{~W}[\mathrm{bcg} / \mathrm{l}+\overline{\mathrm{a}} / \mathrm{g}$ hcg/l] Breaking Force FB $=9.60$

$$
\mathrm{KN}
$$

\subsection{Vertical Force (FV)}

$\mathrm{FV}=3 / 2[$ Static + dynamic load $]$

$\mathrm{FV}=3 / 2[\mathrm{~W} * \mathrm{bcg} / \mathrm{l}+\mathrm{m} * \overline{\mathrm{a}} * \mathrm{hcg} / \mathrm{l}]$

$=3 / 2 \mathrm{~W}[\mathrm{bcg} / \mathrm{l}+\overline{\mathrm{a}} / \mathrm{g} * \mathrm{hcg} / \mathrm{l}]$

Vertical Force FV= $19.86 \mathrm{KN}$

\subsection{Lateral Force (FL)}

$\mathrm{FL}=\mathrm{W}[$ Static + dynamic load $]$ $\mathrm{FL}=\mathrm{W}[\mathrm{bcg} / \mathrm{l}+\overline{\mathrm{a}} / \mathrm{g} * \mathrm{hcg} / \mathrm{l}]$

Lateral Force $\mathrm{FL}=13.24 \mathrm{KN}$

\subsection{Existing Material Properties}

Table 2: Structural Steel Properties

\begin{tabular}{|l|c|}
\hline Properties of Material & Value \\
\hline Young's Modulus E & $212 \mathrm{GPa}$ \\
\hline Poisson's Ratio $v$ & 0.3 \\
\hline Density $\rho$ & $7865 \mathrm{~kg} / \mathrm{m}^{3}$ \\
\hline Yield Strength $\sigma_{\text {vield }}$ & $440 \mathrm{MPa}$ \\
\hline Ultimate Tensile Strength $\sigma_{u t s}$ & $540 \mathrm{MPa}$ \\
\hline
\end{tabular}

\section{ANALYSIS OF EXISTING UPPER CONTROL}

\section{ARM OF SUSPENSION SYSTEM}

\subsection{Transient Structural Analysis}

Transient dynamic analysis is a technique used to determine the dynamic response of a structure under the action of any general time dependant load. This type of analysis is used to determine the time-varying displacement, stress. For the analysis of existing upper control arm firstly drawing with a 
evaluated dimensions is made in CATIA. After this model imported in ANSYS. Forces and boundary condition applied to the model then meshing of arm using tetrahedral element is done and the result of the analysis shows stresses and deformation of upper control of existing material. The result obtained in analysis shown below:

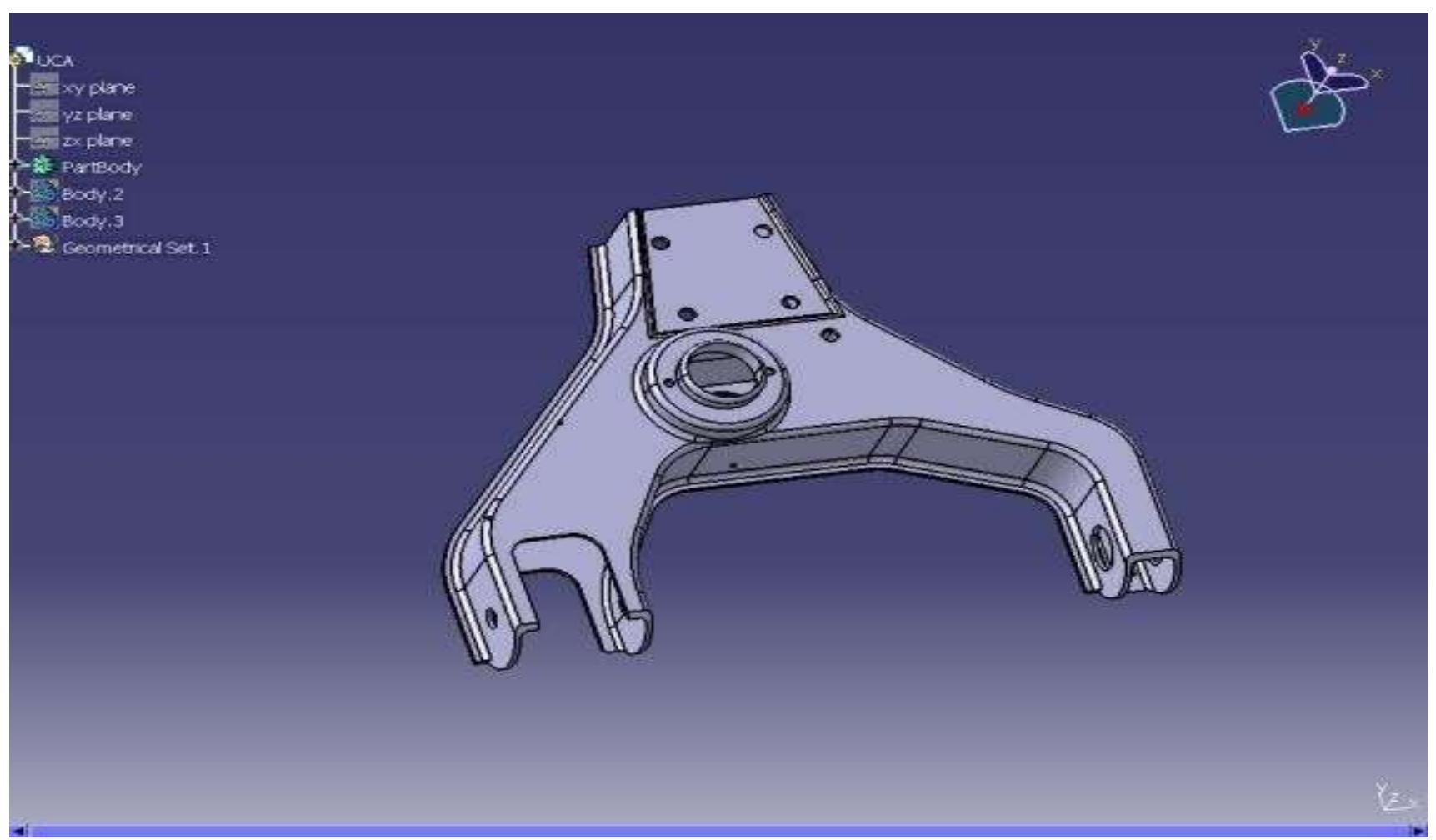

Fig 5: CATIA model of Upper Control Arm

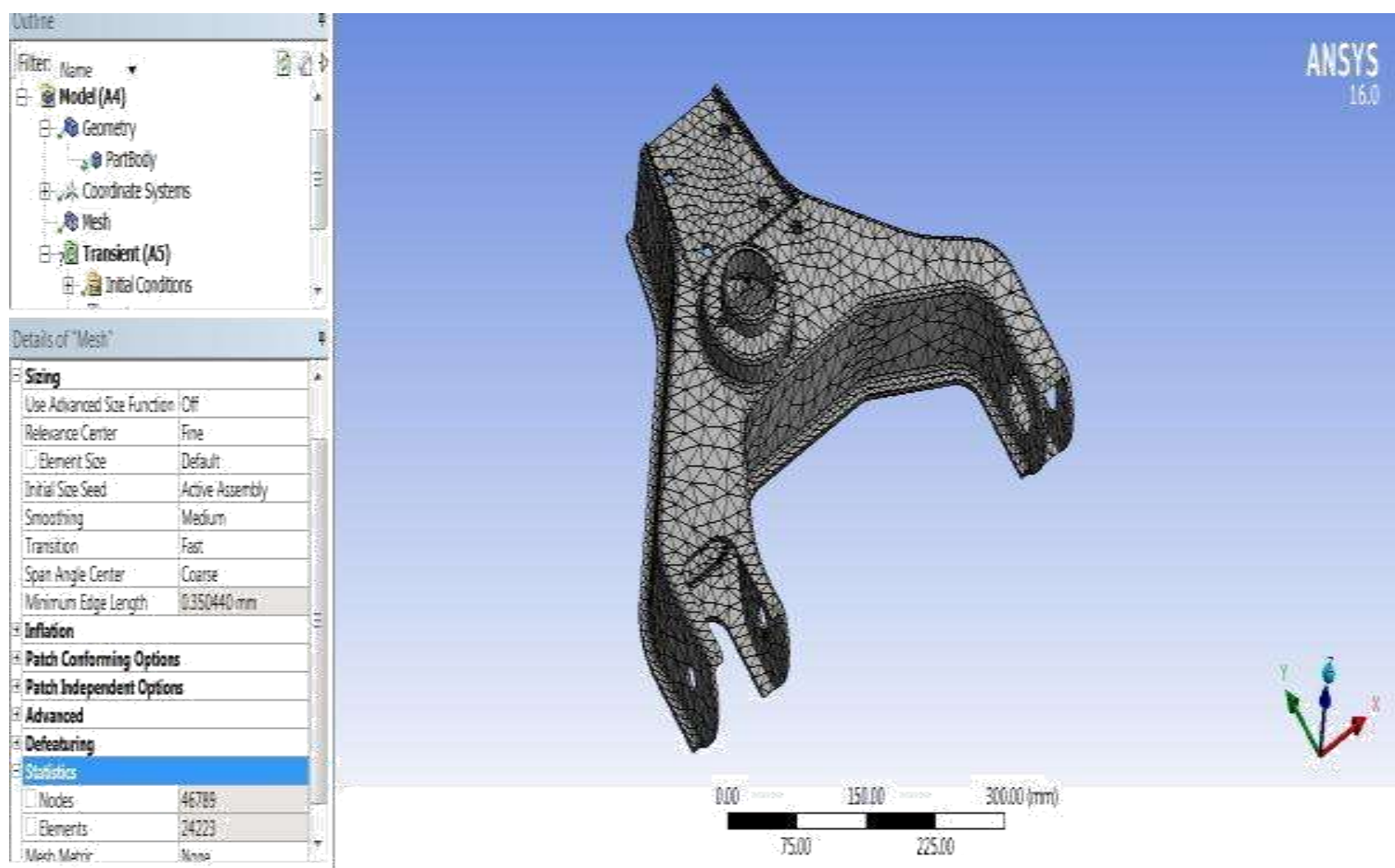

Fig 6: Meshing of Upper Control Arm using Tetrahedral Element 

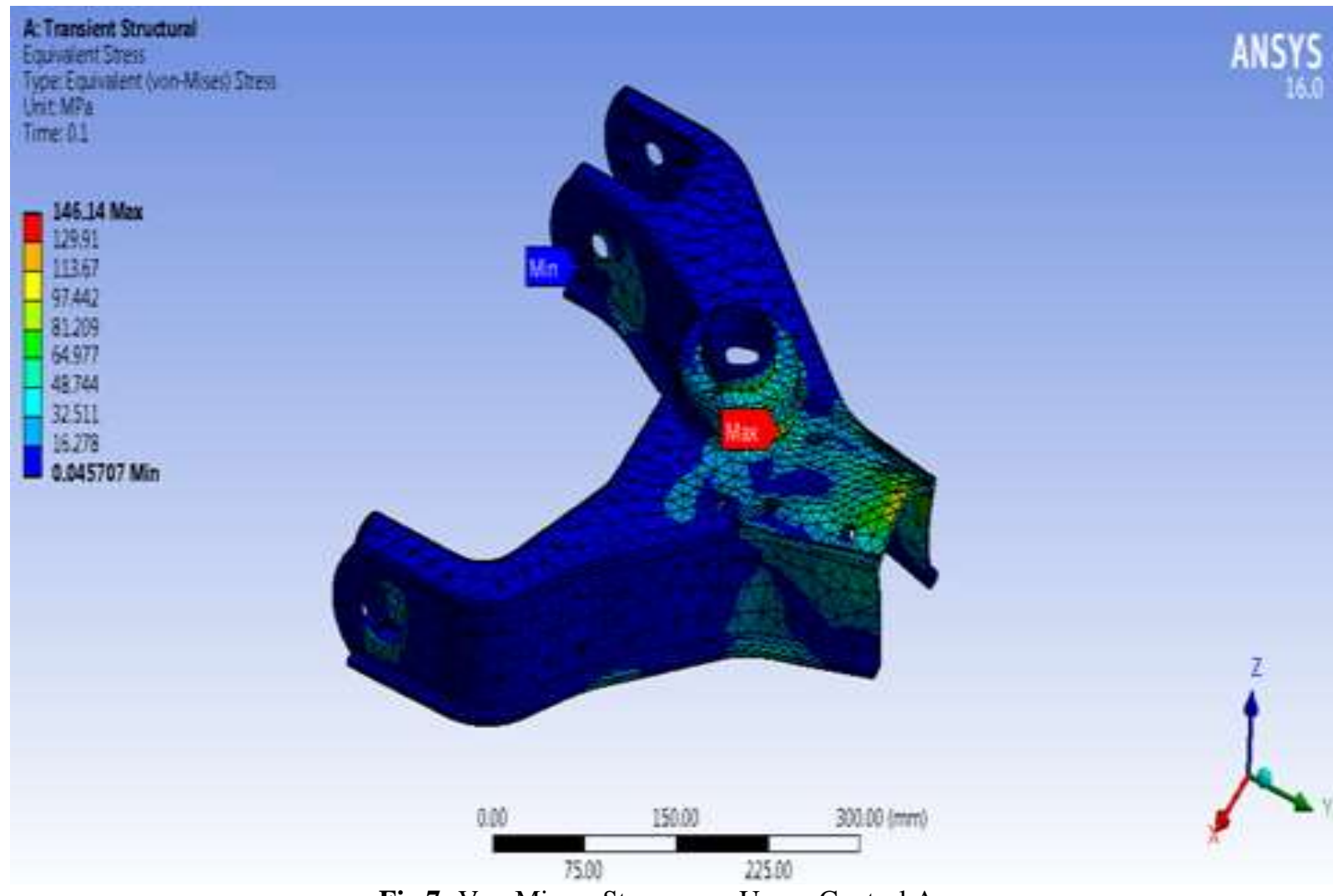

Fig 7: Von Misses Stresses on Upper Control Arm

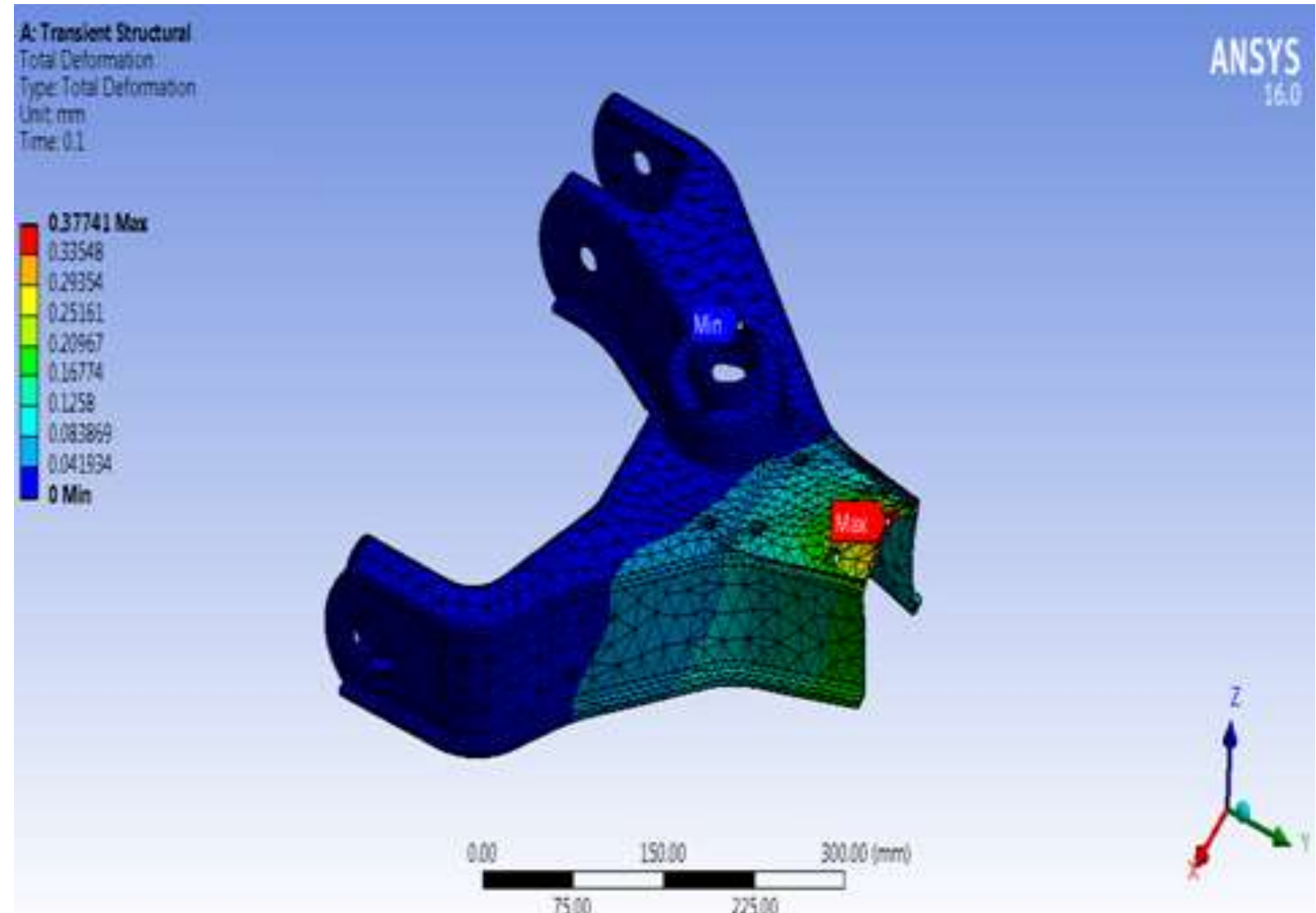

Fig 8: Deformation of Upper Control Arm 
The maximum deformation $0.37741 \mathrm{~mm}$ and von mises stress is $146.14 \mathrm{MPa}$ obtained.

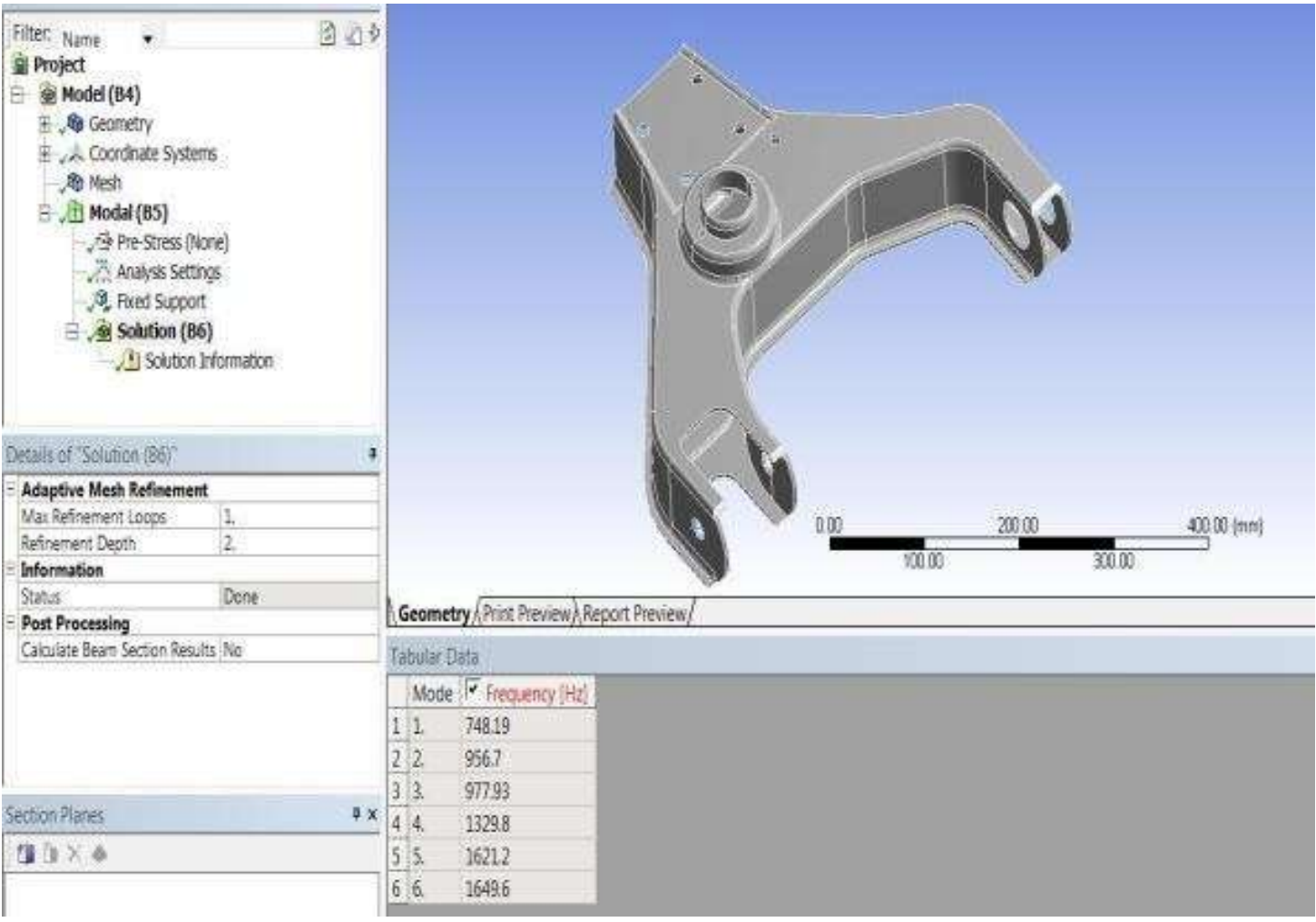

Fig 9: Natural Frequency of Upper Control Arm

\subsection{Modal Analysis}

The study of the dynamic properties of structures under vibrational excitation is Modal analysis. The modal analysis is obtained with different mode sets and their respective deformation. Each mode gives the vibration range in the form of frequency and maximum deformation at that frequency level.. If a structure's natural frequency matches a component's frequency, the structure may continue to resonate and experience structural damage. $1649.6 \mathrm{~Hz}$ maximum frequency above which chances of structural damage to the arm.

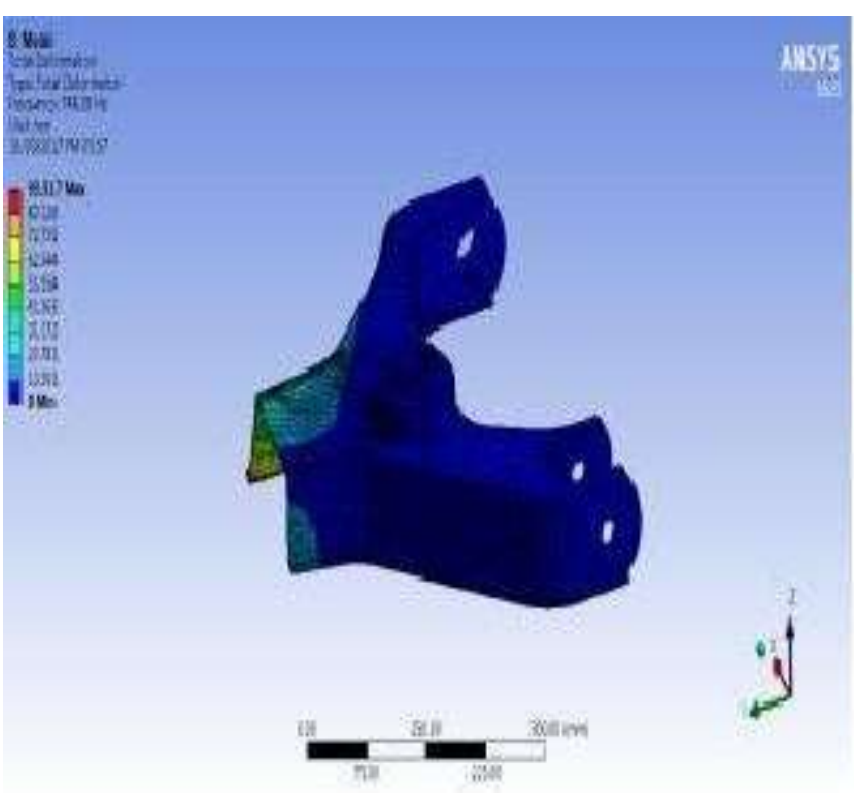

Fig 9a: Mode Shape1

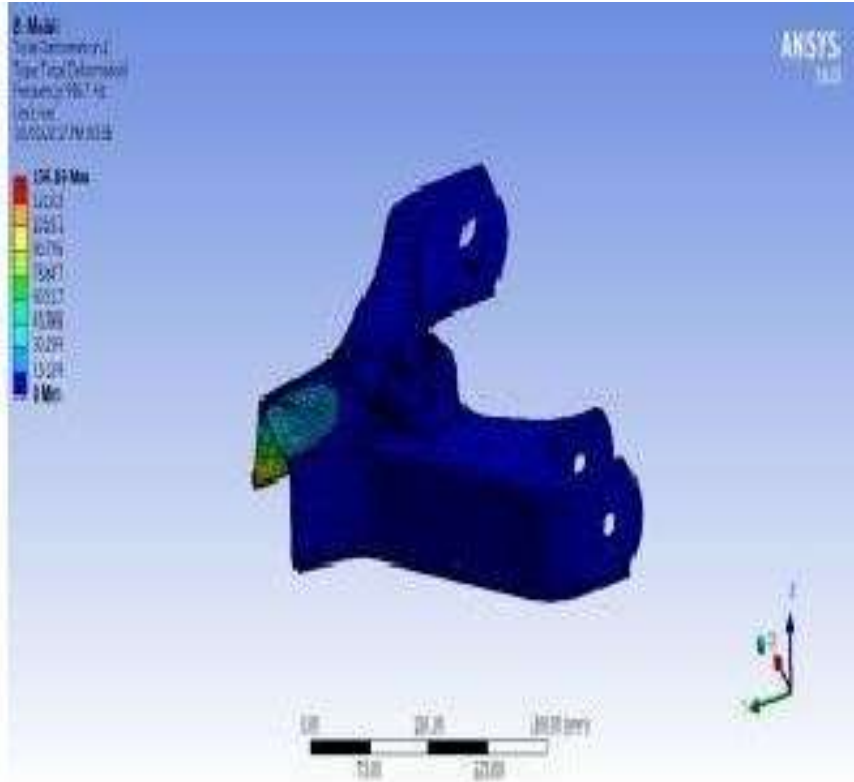

Fig 9b: Mode Shape2 


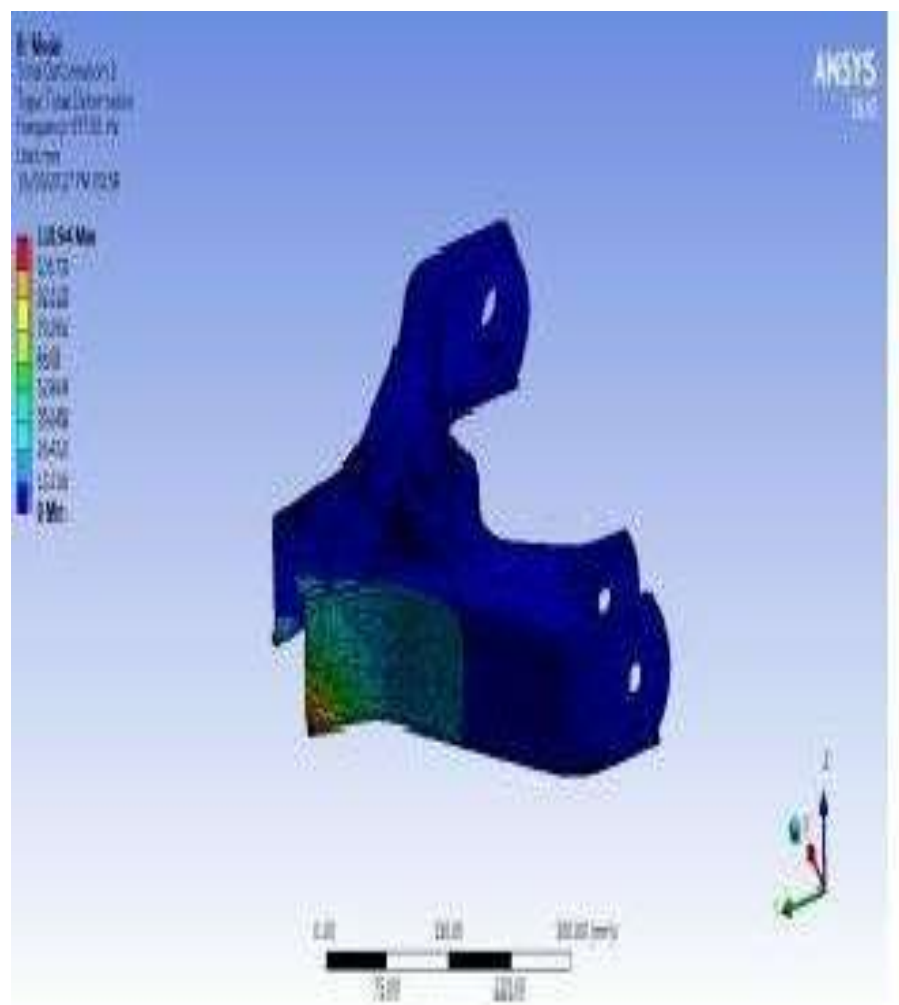

Fig 9c: Mode Shape3

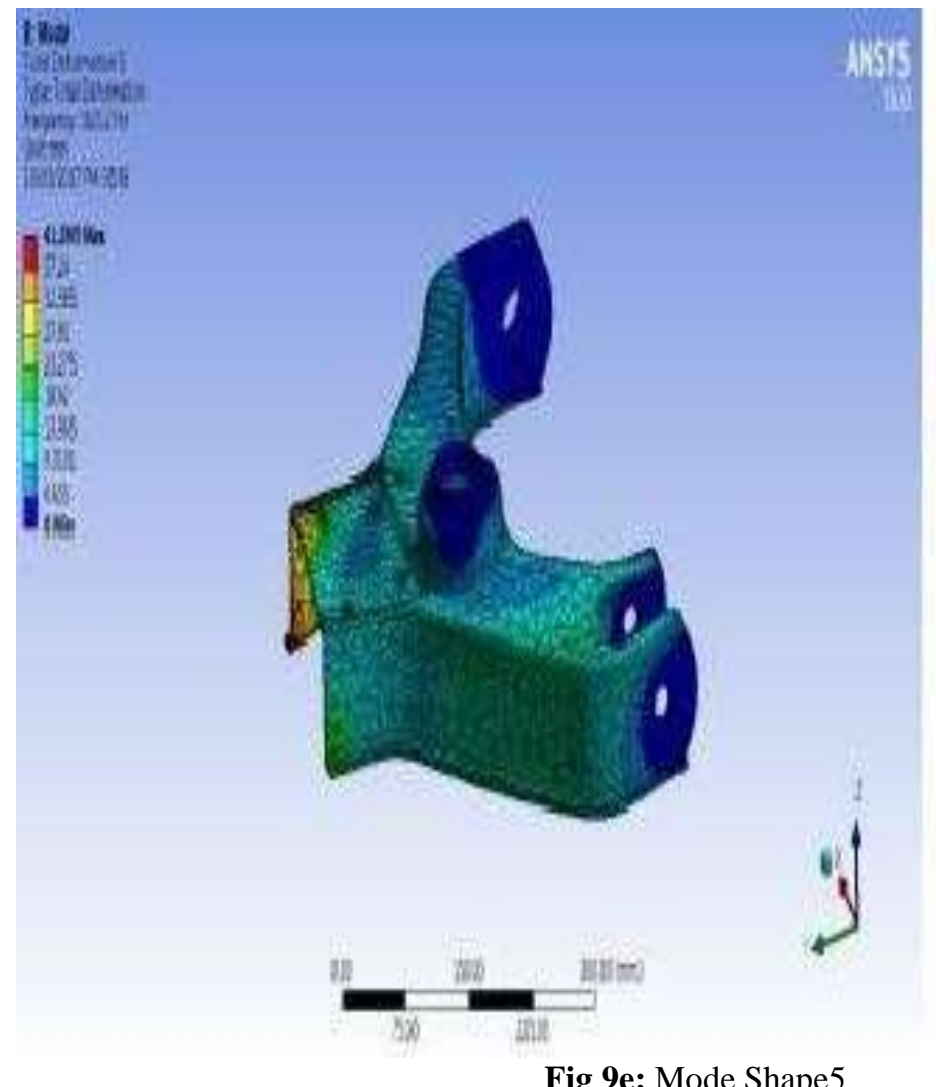

Fig 9e: Mode Shape5

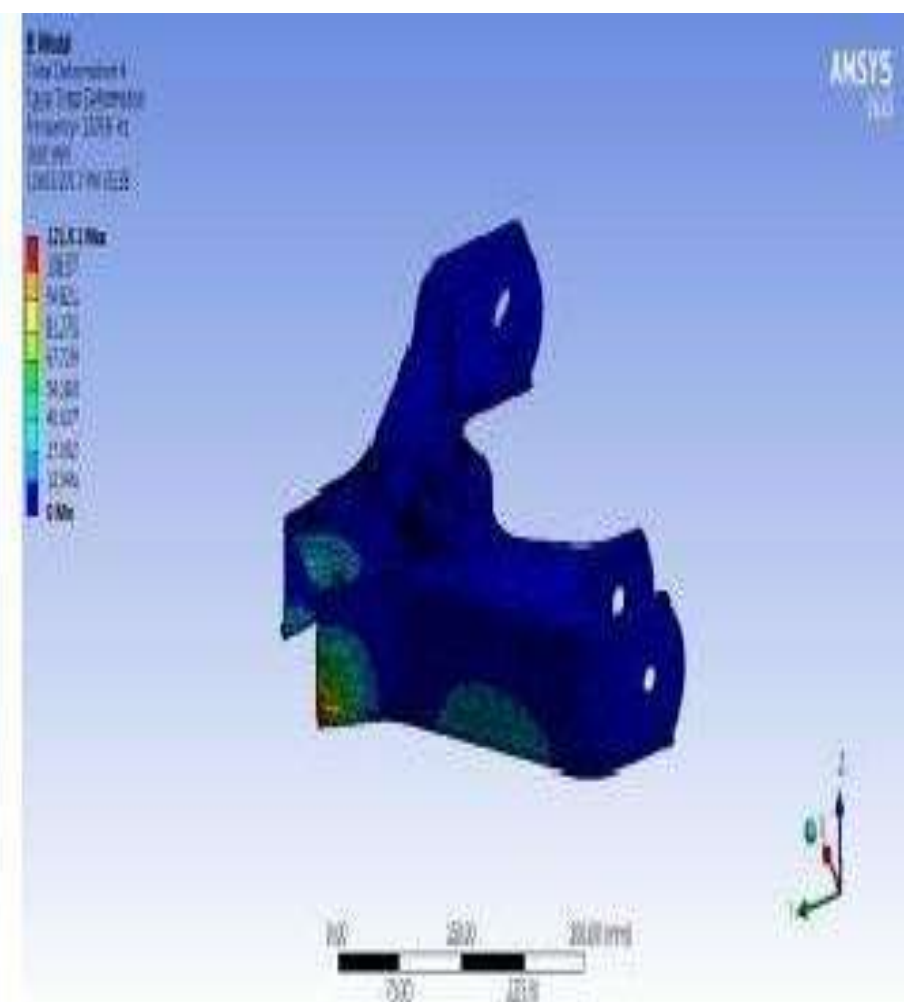

Fig 9d: Mode Shape4

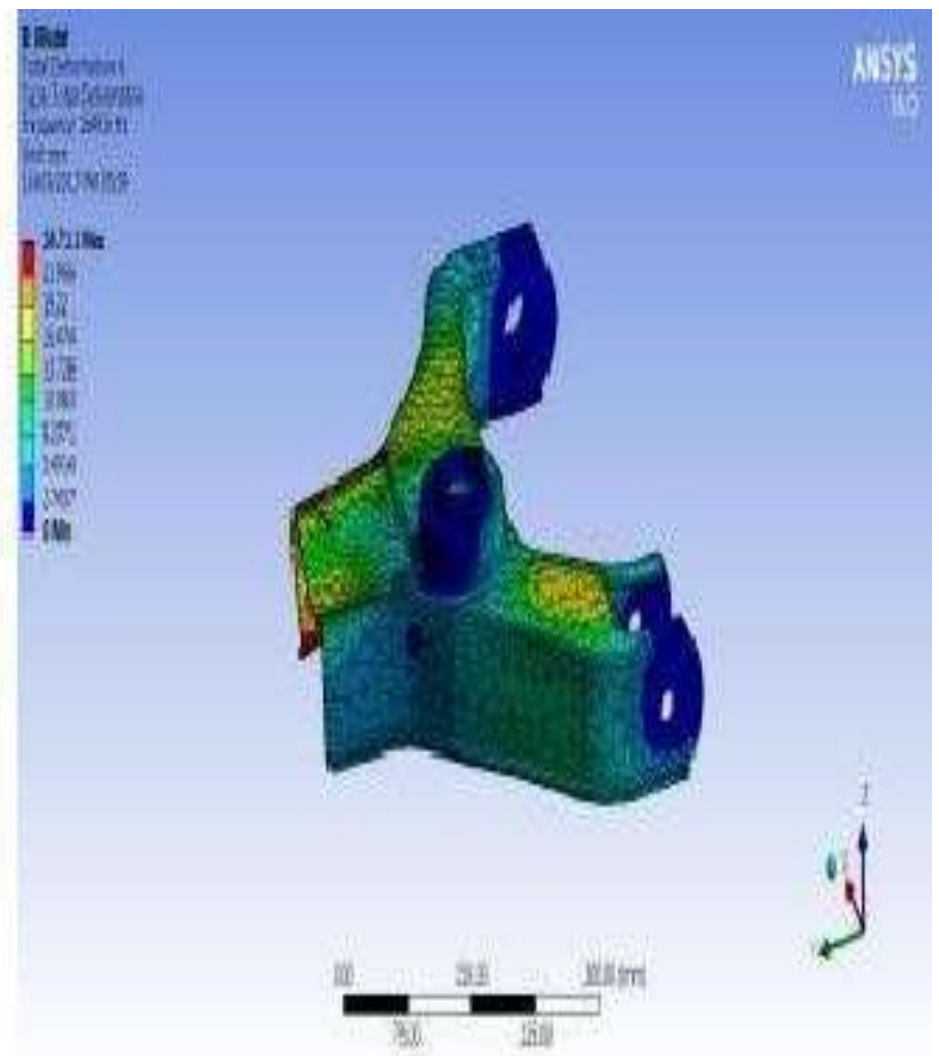

Fig 9f: Mode Shape6 
Table.3: Natural frequency for existing Upper Control Arm

\begin{tabular}{|l|l|l|}
\hline $\begin{array}{l}\text { Mode } \\
\text { Shape }\end{array}$ & $\begin{array}{l}\text { Natural Frequency } \\
\text { Hz }\end{array}$ & $\begin{array}{l}\text { Deformation } \\
\mathbf{m m}\end{array}$ \\
\hline 1 & 748.19 & 93.517 \\
\hline 2 & 956.7 & 136.16 \\
\hline 3 & 977.93 & 118.94 \\
\hline 4 & 1329.8 & 121.91 \\
\hline 5 & 1621.2 & 41.895 \\
\hline 6 & 1649.6 & 24.711 \\
\hline
\end{tabular}

\section{DESIGN AND OPTIMIZATION}

\section{UPPERCONTROL ARM OF SUSPENSION SYSTEM}

Design and Optimization is to find best possible solution under given situations. Here optimization is done considering two parameters based on profile and based on material selection.

\subsection{Optimization based on Profile}

Optimization based on profile in which stresses in arm are taken into consideration Profiles are made based on stresses generated in UCM and at lower stress regions material is removed and likewise iterations are done. Pocket size to be made $35 \mathrm{~mm} \mathrm{cc}$ and radius $20 \mathrm{~mm}$ Figure shown below analysis results of optimization of arm based on profile of Iteration 5. 503.8gm less weight compare to existing upper control arm. Following table shows stresses and deformation for different profile.

Table 4: Analysis results for Modified Profile

\begin{tabular}{|l|c|c|c|c|}
\hline Iteration & Profile & $\begin{array}{c}\text { Weight } \\
\mathbf{K g}\end{array}$ & $\begin{array}{c}\text { Stress } \\
\mathbf{M P a}\end{array}$ & $\begin{array}{c}\text { Deformation } \\
\mathbf{m m}\end{array}$ \\
\hline Iteration 1 & Existing & 8.8919 & 146.14 & 0.37741 \\
\hline Iteration 2 & $\begin{array}{c}\text { Profile } \\
2\end{array}$ & 8.6631 & 140.54 & 0.38072 \\
\hline Iteration 3 & $\begin{array}{c}\text { Profile } \\
3\end{array}$ & 8.5808 & 148.22 & 0.40546 \\
\hline Iteration 4 & $\begin{array}{c}\text { Profile } \\
4\end{array}$ & 8.487 & 161.93 & 0.42525 \\
\hline Iteration 5 & $\begin{array}{c}\text { Profile } \\
5\end{array}$ & 8.3881 & 164.8 & 0.48427 \\
\hline Iteration 6 & $\begin{array}{c}\text { Profile } \\
6\end{array}$ & 8.2867 & 185.51 & 0.53295 \\
\hline
\end{tabular}

Modified arm shown stress and deformation more than existing which is more than existing and weight reduction compare to existing. Stress for modified profile $164.8 \mathrm{Mpa}$ and deformation is $0.48427 \mathrm{~mm}$.

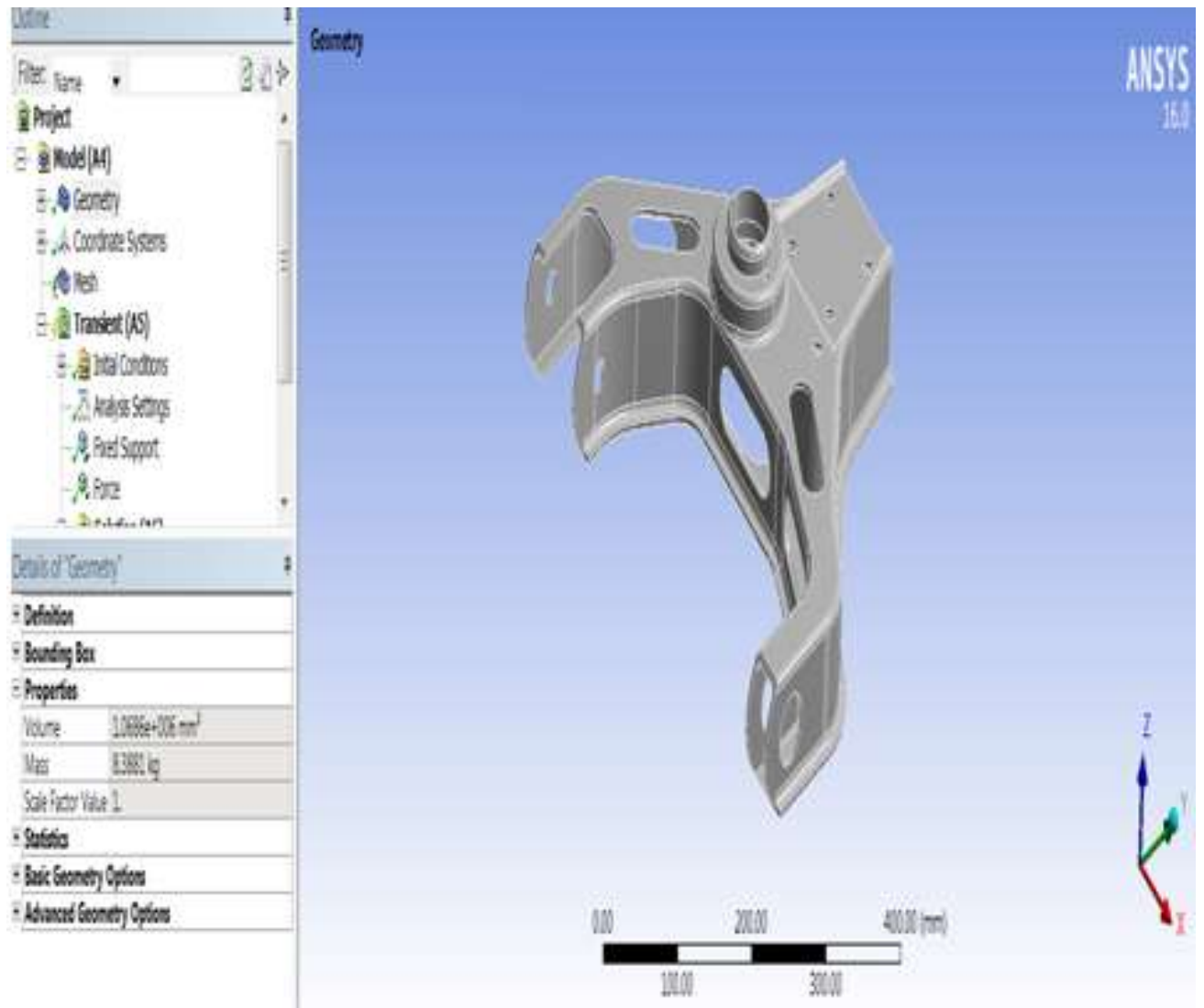

Fig 10: Upper Control Arm with Profile Modification 


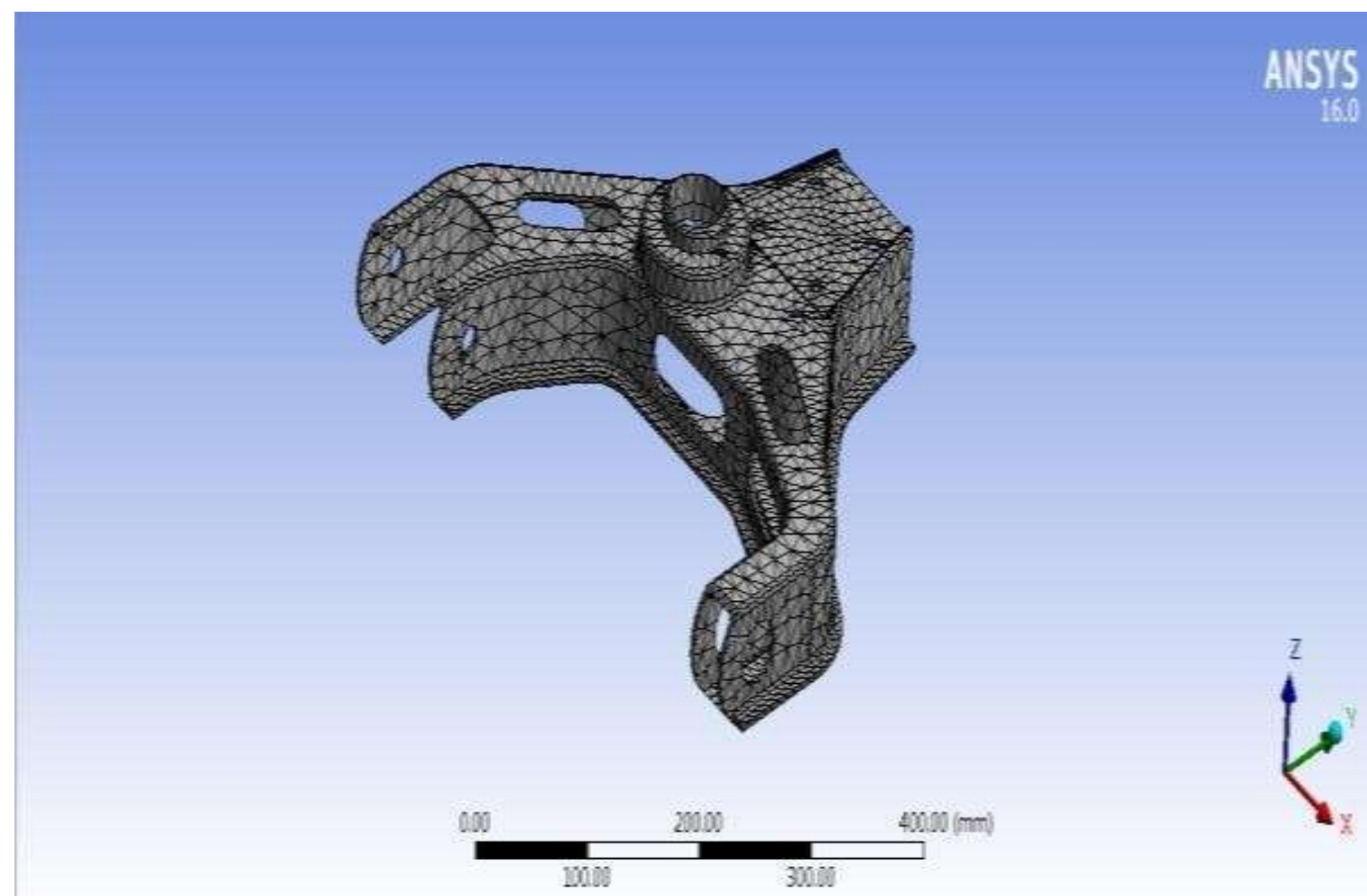

Fig 11: Meshing of UCM using tetrahedral element

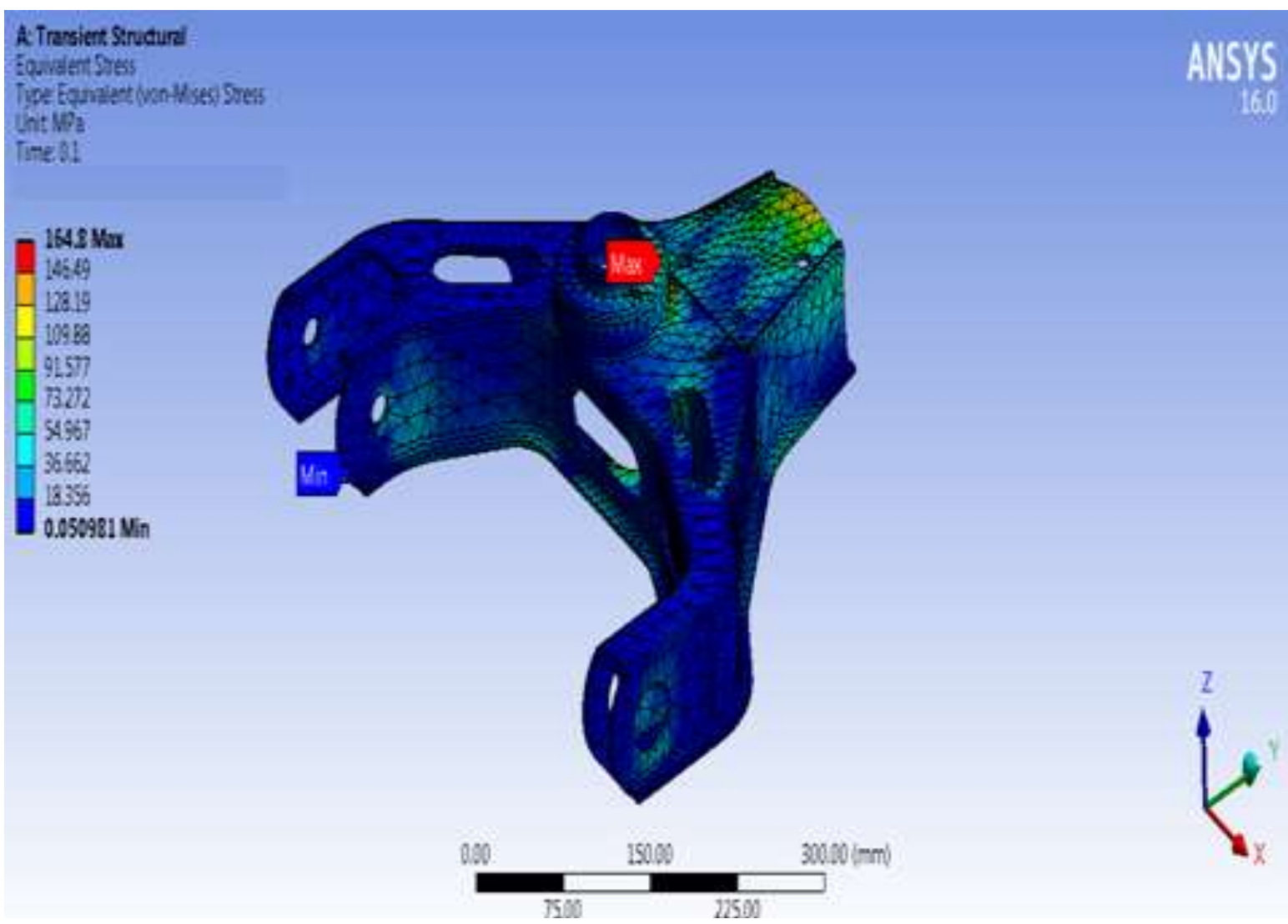

Fig 12: Von Misses Stresses on Upper Control Arm 


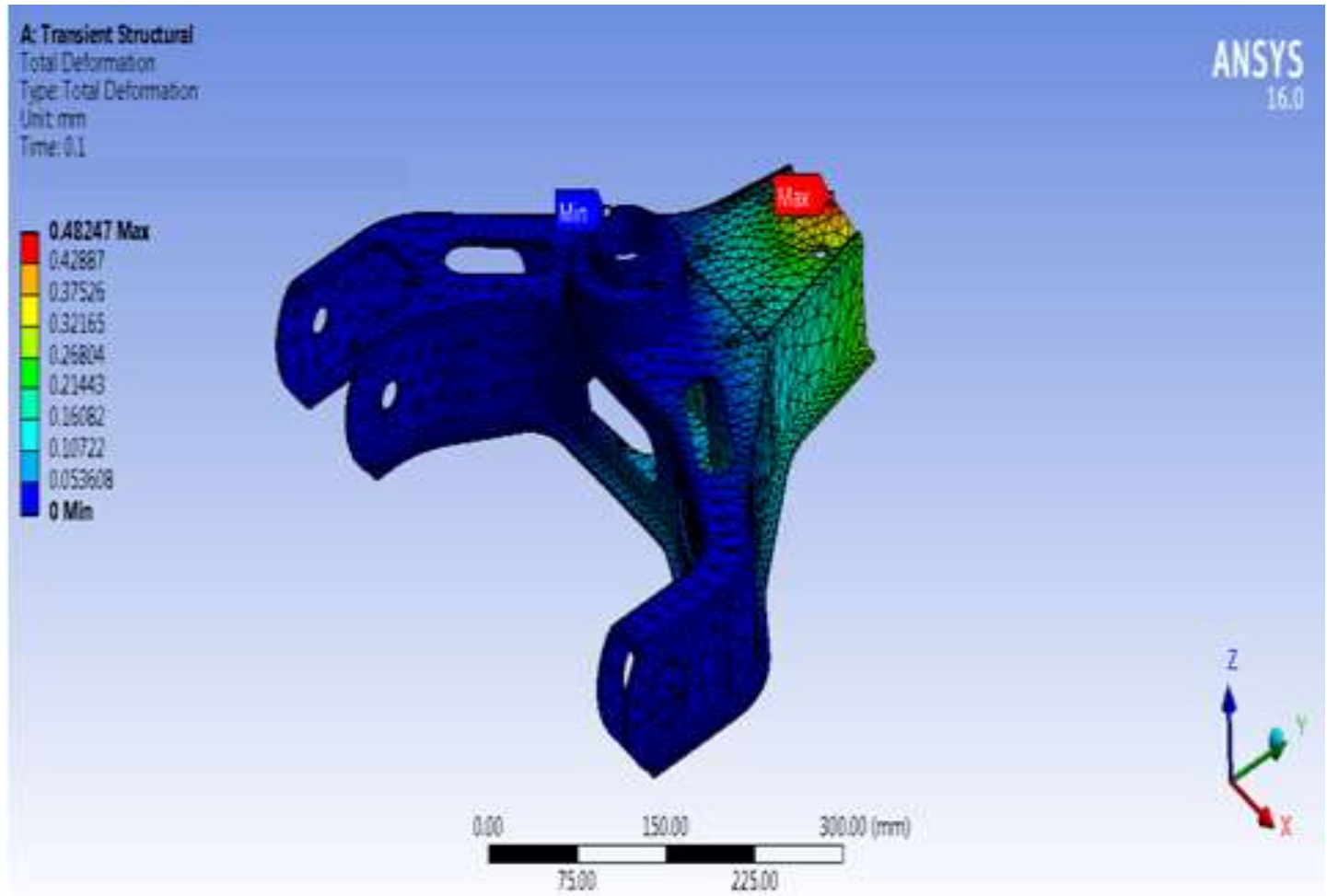

Fig 13: Deformation of Upper Control Arm

\subsection{Optimization based on Material}

\section{Material Selection of Upper Control Arm}

Material to be analyze to find its stress, deformation and taken into account its allowable stress for safety. Best suited material to be selected of upper control arm having better properties(to withstand crushing force). Properties of the alternative material are listed in table below:

Table.5: Properties of Various Materials

\begin{tabular}{|l|l|l|l|l|l|}
\hline $\begin{array}{l}\text { Material } \\
\text { of UCM }\end{array}$ & $\begin{array}{l}\text { Grey } \\
\text { Cast } \\
\text { Iron }\end{array}$ & $\begin{array}{l}\text { Stain- } \\
\text { Less } \\
\text { Steel } \\
\mathbf{3 2 1}\end{array}$ & $\begin{array}{l}\text { Al } \\
\text { Alloy }\end{array}$ & $\begin{array}{l}\text { Mg } \\
\text { Alloy } \\
\text { AZ63 } \\
\text { T1 }\end{array}$ & $\begin{array}{l}\text { Ti } \\
\text { Alloy } \\
\text { Ti- } \\
\text { 6Al- } \\
\text { 4V }\end{array}$ \\
\hline $\begin{array}{l}\text { Yield } \\
\text { Strength } \\
\text { MPa }\end{array}$ & 450 & 515 & 310 & 200 & 880 \\
\hline $\begin{array}{l}\text { Allowable } \\
\text { strength } \\
\text { MPa } \\
\text { FOS 2.0) }\end{array}$ & 225 & 227.5 & 155 & 100 & 440 \\
\hline $\begin{array}{l}\text { Density } \\
(\rho) \text { kg/m }\end{array}$ & 7100 & 8027 & 2700 & 1830 & 4430 \\
\hline $\begin{array}{l}\text { Thermal } \\
\text { Conduct- } \\
\text { vity } \\
\text { W/m k }\end{array}$ & 55.0 & 20.0 & 167 & 77 & 6.7 \\
\hline
\end{tabular}

\begin{tabular}{|l|l|l|l|l|l|}
\hline $\begin{array}{l}\text { Elongatio } \\
\text { n at break } \\
\%\end{array}$ & 15 & 40 & 12 & 6 & 14 \\
\hline
\end{tabular}

From table results below it is stated that Stainless steel is having best result compared to other materials. Deformation above $1 \mathrm{~mm}$ is not accepted. Aluminium and Magnesium has more stress induced than allowable hence can't be considered. Stainless steel has $11.58 \%$ less weight and $11.36 \%$ less stresses. Also has higher allowable strength than structural steel. Therefore selected for testing on UTM.

Table 6: Ansys Results of Various Materials

\begin{tabular}{|c|c|c|c|c|}
\hline $\begin{array}{c}\text { Material of } \\
\text { UCM }\end{array}$ & $\begin{array}{c}\text { Allow- } \\
\text { able } \\
\text { Streng } \\
\text { th } \\
\text { MPa }\end{array}$ & $\begin{array}{c}\text { Stress } \\
\text { MPa }\end{array}$ & $\begin{array}{c}\text { Defor- } \\
\text { mation } \\
\text { mm }\end{array}$ & $\begin{array}{c}\text { Weight } \\
\text { kg }\end{array}$ \\
\hline $\begin{array}{c}\text { Structural } \\
\text { Steel } \\
\text { (Existing) }\end{array}$ & 220 & 146.14 & 0.37741 & 8.919 \\
\hline $\begin{array}{c}\text { Gray Cast } \\
\text { Iron }\end{array}$ & 225 & 183.31 & 0.961 & 7.6936 \\
\hline $\begin{array}{c}\text { Stainless } \\
\text { Steel 321 }\end{array}$ & 257.5 & 131.24 & 0.55002 & 7.9928 \\
\hline $\begin{array}{c}\text { Aluminiuml } \\
\text { Alloy 6061 }\end{array}$ & 155 & 178.51 & 1.4841 & 2.9599 \\
\hline $\begin{array}{c}\text { Magnesium } \\
\text { Alloy AZ63 } \\
\text { T1 }\end{array}$ & 100 & 192.41 & 2.3232 & 1.9234 \\
\hline $\begin{array}{c}\text { Titanium } \\
\text { alloy (Ti- } \\
\text { 6Al-4V) }\end{array}$ & 440 & 176.27 & 1.1016 & 4.9367 \\
\hline
\end{tabular}




\subsection{Modal Analysis of Optimized Upper Control}

\section{Arm for Breaker}

Table 7: Natural frequency and Deformation of Optimized arm

\begin{tabular}{|l|l|l|}
\hline $\begin{array}{l}\text { Mode } \\
\text { Shape }\end{array}$ & $\begin{array}{l}\text { Natural Frequency } \\
\mathrm{Hz}\end{array}$ & Deformation $\mathrm{mm}$ \\
\hline 1 & 409.3 & 54.979 \\
\hline 2 & 660.36 & 57.311 \\
\hline 3 & 786.42 & 97.111 \\
\hline 4 & 890.49 & 110.09 \\
\hline 5 & 1001.2 & 120.27 \\
\hline 6 & 1102.7 & 65.422 \\
\hline
\end{tabular}

\section{EXPERIMENTAL TESTING}

A universal testing machine (UTM), also known as a universal tester, is used to test the tensile strength and compressive strength of materials.

\subsection{Machine Specifications UTM}

Table 8: UTM Specifications

\begin{tabular}{|l|l|}
\hline Max Load Capacity & $100 \mathrm{KN}$ \\
\hline Load Accuracy & Within +/-1\% \\
\hline $\begin{array}{l}\text { Test Space } \\
\text { Censile }\end{array}$ & $680 \mathrm{~mm}$ \\
$620 \mathrm{~mm}$ \\
\hline Piston Stroke & $250 \mathrm{~mm}$ \\
\hline Dimensions & $700 * 610 * 2200 \mathrm{~mm}$ \\
\hline Power Supply & Three-Phase, 240V-50HZ \\
\hline
\end{tabular}

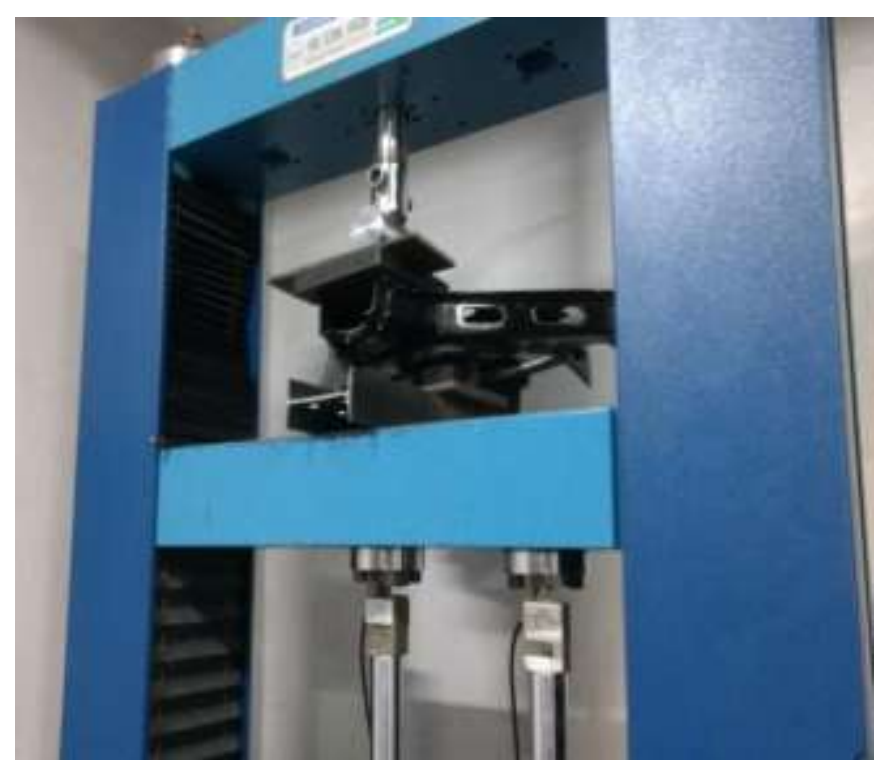

Fig 14: Testing of Arm on UTM

\subsection{Experimental Test Results for Stainless Steel}

\section{1}

Testing of Upper control arm having Stainless Steel 321 material shown in table below:

Table 9: Test Result on UTM

\begin{tabular}{|l|l|l|l|l|l|}
\hline $\begin{array}{l}\text { Weight } \\
\text { (kg) }\end{array}$ & Material & \multicolumn{4}{|l|}{ Deflection, mm(Experimental) } \\
\hline 7.9928 & Stainless & Trial 1 & Trial 2 & Trial 3 & Avg \\
\cline { 3 - 6 } & Steel 321 & 0.57 & 0.58 & 0.58 & 0.577 \\
\hline
\end{tabular}

\section{RESULT AND DISCUSSION}

Upper control arm existing model is analyzed stresses and deformations are found. Maximum von mises stress found to be $146.14 \mathrm{MPa}$ and deformation found to be 0.37741 . Then Optimization of arm for mining crusher is to be done based on profile by making pocket in number of iterations and then selecting best suited material. The maximum stress value for optimized upper control arm for crusher is 131.24MPa. Stresses are less than existing. The final optimized model is capable of handling the loading condition for construction site under safe limit. Deformation of optimized upper control arm is 0.55002 . A comparative study of FEA and experimental result shows $4.58 \%$ error. Optimization reduced the final weight with good strength of upper control arm at obtained boundary condition. Stainless steel 321 is best alternative material to existing one. Modal analysis for optimized mining control arm showed less frequency than existing upper control arm of automotive vehicle .

\section{CONCLUSION}

FEA and optimization techniques can be used for effective performance and weight reduction of mining Breaker upper control arm with better strength. Final optimized model showed stress and deformation values within safe limit and Stainless Steel having suitable alternative to existing material. Natural frequency of optimized control arm less than existing still value is allowable. Optimization of arm shows $11.58 \%$ weight reduction than existing.

\section{FUTURE SCOPE}

a) Vibration testing can be done.

b) Experimental testing on vehicle can be done with high end equipments and facilities.

\section{ACKNOWLEDGEMENT}

I take this opportunity to thank the people who helped me through this project. I am grateful Mr.R.N.Bhatt,Manager (Production) Sandvik Asia Pvt.Ltd, Dr.N.P.Gulhane, HOD of Mech Dept., Dr.S.S.Naik, PG Coordinator. I would like to express my sincere thanks to my guide Dr.W.S.Rathod for his valuable guidance wherever required. 


\section{REFERENCES}

[1] Jagwinder Singh, Siddhartha Saha, -Static Structural Analysis of Suspension Arm Using Finite Element Method\|, International Journal of Research in Engineering and Technology eISSN: 2319-1163, pISSN: 2321-7308.

[2] Gurunath Biradar, Dr. Maruthi B H, Dr. Channakeshavalu, -Life Estimation Of Double Wishbone Suspension System Of Passenger Carl, International Journal for Technological Research in Engineering Volume 2, Issue 12, August-2015, ISSN: $2347-4718$.

[3] A. Rutci, -Failure Analysis of a Lower Wishbonell, Special issue of the International Conference on Computational and Experimental Science and Engineering, Vol. 128 (2015).

[4] Jong-kyu Kim, Seung Kyu Kim, Hwan-Jung Son, Kwon-Hee Lee, Young-Chul Park, -Structural Design Method of a Control Arm with Consideration of Strengthll, proceedings of the 9th wseas int. conference on applied computer and applied computational science.

[5] B. Sai Rahul, D.Kondaiah and A.Purshotham,-Fatigue Life Analysis of Upper Arm of Wishbone Suspension Systemll, Journal of Mechanical and Civil Engineering, e-ISSN: 22781684, p-ISSN: 2320-334X, Volume 11, Issue 5 Ver. V (Sep-Oct. 2014), PP 36-40.

[6] Prof. A. M. Patil, Prof. A.S. Todkar, Prof. R. S.Mithari, Prof. V. V. Patil, -Experimental \& Finite Element Analysis of Left Side Lower Wishbone Arm of Independent Suspension Systeml, IOSR Journal of Mechanical and Civil Engineering (IOSRJMCE)

[7] Lihui Zhao, Songlin Zheng, Jinzhi Feng, Qingquan Hong, -Dynamic Structure Optimization Design of Lower Control Arm Based on ESLll, Research Journal of Applied Sciences, Engineering and Technology 4(22): 4871-4878, 2012, ISSN: 2040- 7467.

[8] N.A. Kadhim, S. Abdullah, A.K. Ariffin, S.M.Beden -Fatigue Failure Behaviour Study of Automotive Lower Suspension Armll, Key Engineering Materials Vols. 462-463 (2011) pp 796- 800.

[9] V.V. Jagirdar, M.S. Dadar, and V.P. Sulakhe,-Wishbone Structure for Front Independent Suspension of a Military Truckll, Defence Science Journal, Vol. 60, No. 2, March 2010, pp. 178-183.

[10] Y.Nadot, V. Denier - Fatigue failure of suspension arm: experimental analysis and multiaxial criterionl, Elsevier, Engineering Failure Analysis 11 (2004) 485-499. 